\title{
Promoting Long-Lasting Learning through Instructional Design
}

\author{
Patrik Hultberg \\ Kalamazoo College \\ Patrik.Hultberg@kzoo.edu \\ David Santandreu Calonge \\ Canadian University Dubai \\ Eugene Lee \\ Sungkyunkwan University
}

\begin{abstract}
Passively listening to a lecture (deWinstanley \& Bjork, 2002), skimming a textbook chapter, or googling for an answer to a homework problem is not conducive to deep and lasting high-order learning. At the same time, presenting complex concepts in problem-based classes might overload students' working memory capacity. Effective student learning necessitates students to process information in their working memories, as well as storing information, facts and skills, in their long-term memories. Students must then be able to retrieve this information into their working memory in the future, in order to apply the information to new situations. That is, students must be able to recognize the characteristics of a future situation or problem and correctly retrieve the appropriate information stored in their long-term memory (Kirschner, Sweller, \& Clark, 2006) to tackle the issue. Using the framework of Cognitive Load Theory, this article proposes an instructional model that promotes five strategies for learning and teaching; i.e. spacing, retrieval practice, elaboration, interleaving, and concrete examples, to effectively help students store and retrieve information from their long-term memory.
\end{abstract}

Keywords: Learning and Teaching strategies, cognitive load theory, instructional design.

\section{Introduction and Background}

"Forgetting focuses remembering and fosters learning; remembering generates learning and causes forgetting; learning causes forgetting, begets remembering, and supports new learning” Bjork, (2011, p 16).

There is very limited research in the past few years that focuses on classroom learning strategies applied to education, human learning and memory, information processing and retrieval to improve learning and teaching. To date, few exploratory studies for instance examined the amount of information that can be stored in long-term memory. Previous research found no limitations on the amount of information that students could retrieve from long-term memory to working memory over indefinite periods of time (Kirschner et al.; 2006). In fact, it was argued 
that the most important aim of all instruction was to alter long-term memory (Kirschner et al., 2006). Other studies also found that moving information along the memory continuum entailed some hard work. This was articulated by Zull (2002) when he argued that students had to repeatedly use their brains to receive and process sensory input in order to learn something, retain information long-term and transfer it to other activities. Constant retrieval from memory and repeated practice through tests for example is, according to research by Karpicke \& Roediger (2008), considered more beneficial to enhance long-term retention and transfer than repeated studying. Furthermore, Kirschner et al. (2006) suggested that minimally guided instruction would most likely be ineffective for students as it did not "support the cognitive processing necessary for learning," an argument that is contrary to a certain number of studies on problem-based learning or creativity. A number of studies have shown that when students receive minimal guidance and feedback in discovery or exploration-based curricula, they experience feelings of loss and frustration, which often lead to misconceptions. In fact, a review of the literature on discovery learning by Mayer (2004) concluded that instructor-guided discovery appeared to offer "the best method for promoting constructivist learning."

In summary, much of the theoretical literature has established that students needed to be guided and challenged in a range of activities, provided with multiple opportunities to retrieve, use and reuse information over time to promote long-term retention and transfer. However, few writers have been able to draw on any systematic strategies and practical suggestions to address this issue. The purpose of this paper is therefore to review recent research on cognitive architecture, cognitive load theory and propose instructional recommendations that promote five strategies for learning and teaching.

\section{Cognitive Architecture}

Learning for long-term retention and transfer is complex and arduous or as Brown et al. (2014) put it, what we, as teachers, are beginning to understand is that "learning is deeper and more durable when it's effortful” (Brown et al., 2014). What should students do to make learning, in effect, more difficult? Cognitive psychology provides many suggestions.

To effectively help students to store information in their long-term memory and then accurately and efficiently be able to retrieve such knowledge in the future, we should consider the following structures that constitute human cognitive architecture.

A cognitive architecture refers to how memory structures are organized to process and store information. It has been suggested that humans are only conscious of the contents of their working memory (Sweller, van Merrienboer, \& Paas, 1998). All other cognitive functions are hidden in long-term memory until retrieved into working memory. This is significant due to working memory's severe limitations: studies have shown that about seven elements of information can be held at a time and only for about 30 seconds without rehearsal (Miller, 1956; Sweller, 2004; Baddeley, 2010). In addition, since working memory is used to process information, its actual capacity is even more limited and this, in consequence, reduces the number of items that can be dealt with simultaneously.

These physical limitations on working memory imply that instructional choices and design must be carefully considered to accommodate students' limited capacity. In fact, anything beyond the simplest cognitive activities may have an overwhelming impact on their working memory. The effective use of long-term memory may help circumvent these restrictions. Longterm memory is considered to be practically unlimited (Kirschner et al., 2006) and knowledge is 
believed to be stored in long term memory in the form of low level and high level schemas. A schema is an organizing structure, defined as a set of elements of information categorized according to their relationships and future use. Generating increasing numbers of ever richer schemas by combining elements of lower level schemas into higher level schemas is what differentiates a novice from an expert (Sweller, van Merrienboer, \& Paas, 1998). The importance of schemas is thus that a single schema can help combine together many elements (pieces of information) that can then be considered as a single element by a learner's limited working memory. In addition, automated schemas require less processing, as they occur unconsciously, which also helps free up space. Automated schemas allow for automatic performance on familiar tasks (e.g. tying shoes) and by reducing the load on working memory it allows for higher levels of performance.

The usefulness of sophisticated and automated schemas depends on a student's ability to store and retrieve these schemas in the future, on demand. The goal of instructional design is therefore to manage the cognitive load of the student's working memory, in order to allow for the required processing that leads to the construction of schemas and their automation to happen. That is, instructional design must ensure that schema construction and automation are not hampered by unnecessary cognitive overload.

\section{Cognitive Load Theory}

Cognitive load theory was developed out of the study of problem solving by John Sweller in the late 1980s. Sweller (1988) argued that instructional design could be used to reduce cognitive load in learners. According to the theory, during learning information must be held in the working memory until it has been processed sufficiently to transfer into long-term memory. Since the capacity of working memory is limited, when too much information is presented to students at once, it overwhelms them and in consequence much of that information may be quickly be forgotten or lost. Cognitive load theory thus argues that for individuals to learn effectively, their cognitive architecture and the learning environment created by the instructor must be aligned.

Learning, according to cognitive load theory, consists of two critical mechanisms: schema acquisition and the transfer of learned procedures from controlled to automatic processing (Sweller, 1994). Schema acquisition, as mentioned above, is the chunking of information, the organization of elements of information according to how they will be used or dealt with. The processing of information can either be controlled or automatic; controlled processing occurs when information is consciously attended to in working memory; automatic processing occurs without conscious control (Sweller, 1994). Automaticity occurs after extensive practice, including retrieving information from memory on multiple occasions, commonly known as retrieval practice. With sufficient practice, a procedure (such as changing gears when driving) can be carried out with minimal conscious effort; i.e. with minimal working memory cognitive load. With automation, familiar tasks are performed effortlessly and unfamiliar tasks that partially require automated processes can be learned efficiently as working memory capacity in effect expands (Sweller, van Merrienboer, \& Paas, 1998).

It is important to note that although schemas are stored in long-term memory, in order to construct them, information must first be processed in working memory. The ability of working memory to effectively process information is thus the main concern of cognitive load theory. 
According to cognitive load theory there are three types of cognitive load: intrinsic, extraneous, and germane cognitive load.

- Intrinsic cognitive load is determined by the effort associated with the complexity of the material; i.e. the level of interactivity between elements.

An element is anything that has been or needs to be learned, such as a concept. Element interactivity is a measure of the number of elements that must be processed simultaneously in working memory. Low-element interactivity tasks require low cognitive load, e.g. learning basic facts or a few words in Korean. These elements can be learned serially, rather than simultaneously. High-element interactivity tasks must be processed simultaneously in order to be learned, processed or understood. In fact, our common notion of understanding is applied to high-element interactivity tasks; that is, we understand something when high-element interactivity material can be held simultaneously in our working memory.

The intrinsic cognitive load of a particular piece of information cannot be altered by instructional design. However, an instructor may be able to control the intrinsic load by presenting content and material in certain ways; e.g. simple to complex or part-whole sequencing. A large number of interactive elements for a novice learner may be a single element (a schema) for someone with more expertise. There are two important implications:

(1) The instructor needs to know the level of expertise of the learners, and

(2) Instructional design needs to gradually build up the learners' schema, from basic to complex or parts to whole.

- Extraneous cognitive load is the load caused by how content or tasks are presented to students.

According to cognitive load theory, the cognitive load imposed by the instructional decisions made should be carefully considered. Purposeful instructional decisions and interventions can therefore help adjust extraneous cognitive load. Instructors should aim to reduce the extraneous cognitive load which will allow students to either process more elements in working memory or elements of higher interactivity. Irrelevant and peripheral information or poor layout may cause overloads in the working memory and negatively affect students' storage of information. Another important benefit of instructional design that carries low extraneous load is the possibility of introducing learning strategies that lead to greater schema construction or automation. That is, instructional techniques that increase germane cognitive load.

- Germane cognitive load is cognitive load that facilitates the construction and automation of schemas.

The difference between extraneous and germane cognitive loads is theoretically questionable (de Jong, 2010; Debue, \& van de Leemput, 2014), nevertheless, the distinction is operationally relevant and the implication is that instructional design should aim to decrease extraneous cognitive load and focus on increasing germane cognitive load, while maintaining total cognitive load at manageable levels (to avoid cognitive overload). 
In summary, the nature, complexity and element interactivity of a task (intrinsic load) will impact students' cognitive load. Extraneous load is caused by confusing presentation, unnecessary activities, or superfluous information. Germane load is the effective processing of information that contributes to learning.

The goal of instructional design is therefore to adopt a number of purposeful strategies in the learning environment whose role is to control intrinsic load, reduce extraneous load and increase germane load, as shown in Figure 1.

Figure 1. The effect of instructional design on cognitive load

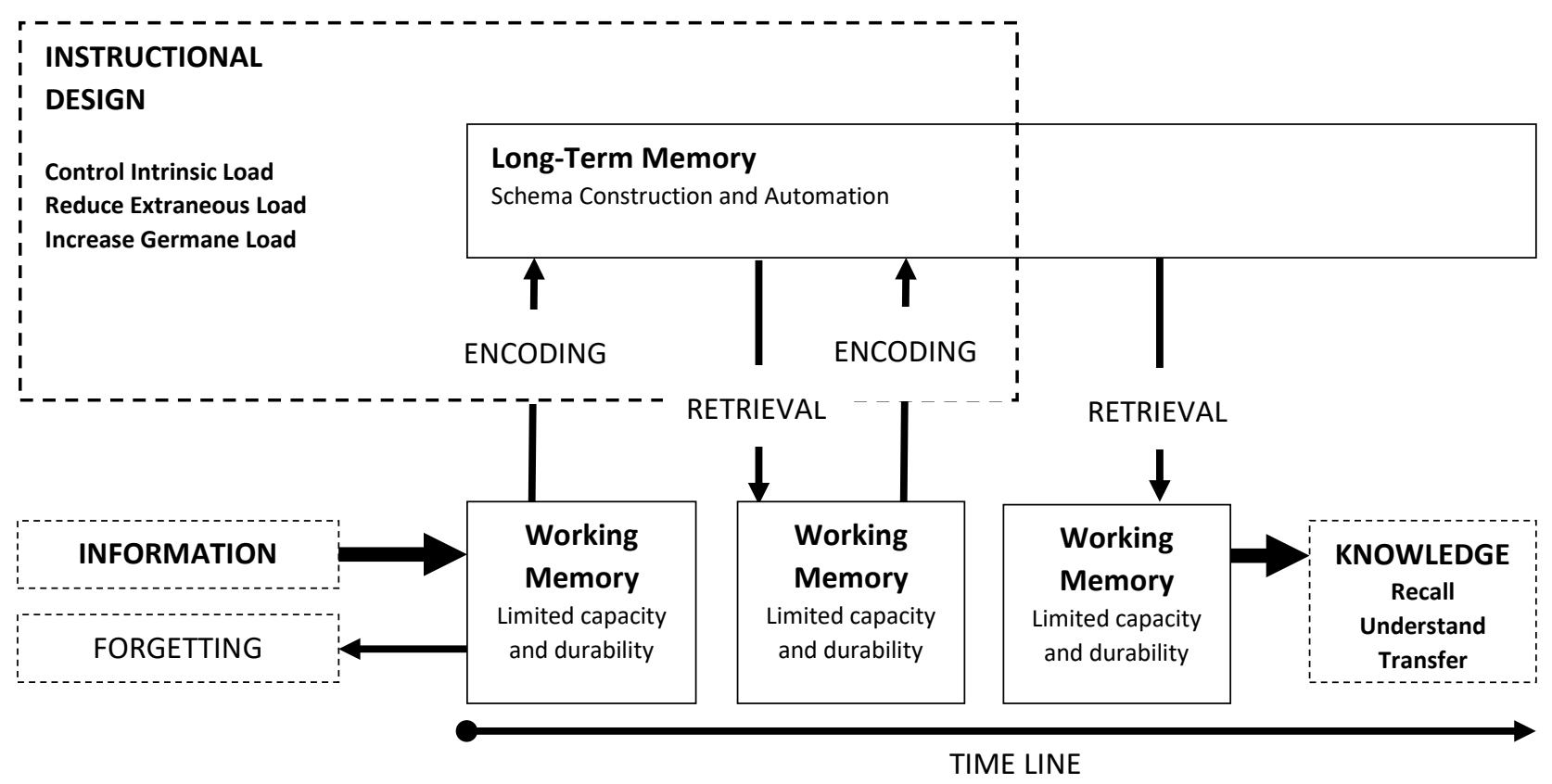

As indicated in Figure 1, instruction should be designed in ways that facilitate learners' ability to process information in working memory, encode that information into long-term memory by schema construction and automation, and finally allow for efficient retrieval of stored information at a future point in time.

In summary, cognitive load theory makes learning more effective by suggesting instructional methods that reflect these processes. The theory also suggests that instructional techniques that ask students to engage in activities that do not facilitate schema acquisition and automation are likely to be ineffective.

It is therefore proposed that five strategies for learning and teaching, i.e. spacing, retrieval practice, elaboration, interleaving, concrete examples, may help increase germane load. As implied in Figure 1, an important goal of instructional design is to create a suitable cognitive "space" for the adoption of evidence-based learning strategies, which main role is to control intrinsic load and decrease extraneous load. Table 1 presents an overview of the five strategies and their application. 
Table 1. Overview of Instructional Strategies

\begin{tabular}{|c|c|c|c|c|c|c|c|}
\hline & \multicolumn{4}{|l|}{ CONTENT } & \multicolumn{3}{|c|}{ PRESENTATION } \\
\hline \multirow[t]{2}{*}{$\begin{array}{l}\text { Control } \\
\text { Intrinsic } \\
\text { Load }\end{array}$} & \multicolumn{4}{|c|}{$\begin{array}{l}\text { Match difficulty to student expertise. } \\
\text { Conduct knowledge analysis. } \\
\text { Consider degree of element interactivity. } \\
\text { Simple-to-complex sequencing. }\end{array}$} & \multicolumn{3}{|c|}{$\begin{array}{l}\text { Part-whole sequencing. } \\
\text { Time allotment. } \\
\text { Off-loading devices }\end{array}$} \\
\hline & \multirow{2}{*}{\multicolumn{2}{|c|}{$\begin{array}{l}\text { SPLIT-ATTENTION } \\
\text { Avoid cognitive load } \\
\text { associated with } \\
\text { mentally integrating } \\
\text { disparate sources of } \\
\text { information. }\end{array}$}} & \multicolumn{2}{|c|}{ LACKING SCHEMA } & \multicolumn{2}{|c|}{ "REDUNDANCY } & "DUAL CODING \\
\hline \multirow[t]{2}{*}{$\begin{array}{l}\text { Reduce } \\
\text { Extraneous } \\
\text { Load }\end{array}$} & & & \multicolumn{2}{|c|}{$\begin{array}{l}\text { Ensure students } \\
\text { possess appropriate } \\
\text { schema to avoid } \\
\text { means-ends analysis. }\end{array}$} & \multicolumn{2}{|c|}{$\begin{array}{l}\text { Avoid multiple sources of } \\
\text { material that contains the } \\
\text { same information. }\end{array}$} & $\begin{array}{l}\text { Present content as a } \\
\text { combination of visual } \\
\text { and auditory material. }\end{array}$ \\
\hline & SPACING & $\begin{array}{l}\text { RET } \\
\text { PRA }\end{array}$ & $\begin{array}{l}\text { IEVAL } \\
\text { TICE }\end{array}$ & ELABOR & ATION & INTERLEAVING & $\begin{array}{l}\text { CONCRETE } \\
\text { EXAMPLES }\end{array}$ \\
\hline $\begin{array}{l}\text { Raise } \\
\text { Germane } \\
\text { Load }\end{array}$ & $\begin{array}{l}\text { Distributing } \\
\text { practice over } \\
\text { time. }\end{array}$ & $\begin{array}{l}\text { Recr } \\
\text { some } \\
\text { in the } \\
\text { mem }\end{array}$ & $\begin{array}{l}\text { aing learned } \\
\text { past from } \\
\text { py. }\end{array}$ & $\begin{array}{l}\text { Explainin } \\
\text { describing } \\
\text { details. M } \\
\text { connectio } \\
\text { own expe } \\
\text { and previc } \\
\text { material. }\end{array}$ & $\begin{array}{l}\text { and } \\
\text { deas in } \\
\text { xing } \\
\text { to } \\
\text { ences } \\
\text { s }\end{array}$ & $\begin{array}{l}\text { Mixing related but } \\
\text { distinct material } \\
\text { during learning } \\
\text { sessions. }\end{array}$ & $\begin{array}{l}\text { Linking abstract } \\
\text { concepts to } \\
\text { concrete } \\
\text { examples } \\
\text { whenever } \\
\text { possible. }\end{array}$ \\
\hline
\end{tabular}

\section{Implications for Instructional Design}

Given our knowledge of human cognitive architecture and the implications of cognitive load theory, what are the practical implications on instructional design? What should the instructor do, or avoid, in the classroom? This article argues that the instructor needs to raise students' germane cognitive load by adopting five evidence-based learning strategies. However, in order to do so, the instructor must control students' intrinsic cognitive load and reduce extraneous cognitive load. These actions will ensure that the total processing capacity of the learner's working memory is not exceeded, especially if the material covered is of high element interactivity.

The following part deconstructs these ideas, and offers practical suggestions, in the form of three propositions.

Proposition \#1: To achieve learning, any instructional practice must avoid cognitive overload.

Students have limited working memory capacities that can be overwhelmed by tasks that are cognitively too demanding (Deans for Impact, 2015; Chandler \& Sweller, 1992; Moreno, 2006). Instructional design must therefore ensure that content and facilitation do not result in cognitive overload of the learner's working memory.

The first step is to control or manage the intrinsic cognitive load of the material presented. In general, the intrinsic cognitive load is invariable. That is, the nature of the material determines the intrinsic cognitive load: a basic fact carries a lower cognitive load than a complex concept that requires deep understanding. One reason is that a fact can be learned separately and serially and therefore has low element interactivity. Complex concepts, however, require students to simultaneously process many facts and ideas in working memory, which raises 
intrinsic cognitive load. In short, intrinsic load is determined by the complexity of the material covered.

There are ways to control intrinsic load. First of all, as mentioned earlier, learning consists of schema acquisition and a constructed schema becomes a single element in working memory. Hence, by allowing students to gradually "build up" their schemas, from basic facts to increasingly complex concepts, they are able to retain more information in their working memory. It is thus essential to match the complexity of the material to the level of expertise of the students. As students' level of expertise or knowledge increases, their schemas are both more complex and more automated; that is, they are able to recall facts and information effortlessly. Since the intrinsic load of the material depends on the number of separate elements held in working memory, students with more inclusive schemas will be able to process more complex material.

A practical suggestion is for the instructor to conduct a knowledge analysis of the student population; i.e. gauge what they know with the use of, for instance, diagnostic formative assessment, short presentations, readiness assessments, "preparedness” quizzes or even make use of online discussion boards to post diagnostic and exploratory questions. The instructor can then adjust material and pace of presentation to their level of expertise. Another suggestion is to present material sequentially; either from simple to complex or by presenting parts that can be combined to a whole. Both of these approaches start with a few elements and gradually build up the degree of complexity (de Jong, 2010). Each "element" is independently manageable and after all the parts have been clarified and mastered (and a schema acquired), the "whole" concept can be understood.

An alternative approach is to give students more time to process the material, which allows them to serially master parts of the content, as well as switch back and forth between information, thus avoiding cognitive overload (de Jong, 2010). A third possibility is to allow students to "offload" their working memory by giving them an opportunity to write ideas down in a notebook (de Jong, 2010), as mind-maps or on their mobile devices and discuss it with peers. This way, students do not need to keep all elements in working memory simultaneously, as they work through new material.

Once the intrinsic cognitive load has been controlled, the instructor should aim to reduce extraneous cognitive load. Extraneous cognitive load is determined by how content or tasks are presented to students. Purposeful instructional decisions can help reduce extraneous cognitive load, which allows students to either process more elements in working memory or process elements of higher interactivity. Thus the instructor should carefully consider how material is introduced to the class, during lectures, online, and in problem sets. To reduce extraneous cognitive load during content facilitation, the instructor should manage split-attention effects, lack of schema-based knowledge, redundancy, and single modality presentation.

A split-attention effect refers to the cognitive load associated with mentally integrating disparate sources of information. For example, by simultaneously presenting a graph of a concept and a written explanation of the concept immediately below, students' attention will then be "split" between the graph and the text. This split-attention results in raising working memory's cognitive load. The effect can be significantly reduced by integrating all information directly into the graph.

When students who lack schema-based knowledge are asked to analyze complex material, they tend to adopt a means-ends analysis approach. Means-ends analysis is a common, well-known and efficient, problem solving approach that entails trying to establish differences 
between the problem state (i.e. the question to be answered) and the goal state (i.e. the answer to the question) and then finding problem solving tools or actions that can reduce or eliminate those differences (Sweller, 1994). This problem solving approach, although often effective, requires an iterative process and many elements to be concurrently kept in mind. This, as discussed above, tends to exacerbate cognitive load. The implication is that a student may be able to ultimately solve the problem, but will not assimilate the material since the approach bears little resemblance to schema construction. The means-ends approach is therefore distinct and indeed incompatible with learning (Sweller, van Merrienboer, \& Paas, 1998). This incompatibility can be offset by reducing goal-specificity, in other words by letting students figure out on their own and test various hypotheses. This eliminates the number of elements required to be held in working memory (Sweller, 1988). Thereby reducing the cognitive load by eliminating means-ends analysis and, hence, freeing up working memory for schema acquisition. A number of studies have indicated for instance that giving non-specific goals to participants in problem-solving activities led to better learning and completion of the tasks.

A redundancy effect is present when instructional design incorporates multiple sources of material that contains the same information. An example would be to show a PowerPoint slide with a figure and a written paragraph that describes exactly what is occurring in the figure. The duplicity of material, rather than reinforcing learning, leads to an increase in cognitive load and hence may potentially reduce learning. The redundancy effect can be counteracted by coordinating or eliminating unnecessary and often redundant overlapping material.

Finally, since working memory actually consists of two subsystems, an auditory system and a visual system, presentations that use only one of the sub-systems (single modality presentation) are more likely to cause cognitive overload. This effect can be mitigated; i.e. available cognitive capacity can be increased by presenting material as a combination of visual and auditory material (de Jong, 2010). This is often referred to as dual coding. When lecturing, for example, cognitive load can be reduced by presenting some parts of the content in auditory form (i.e. the lecture) and some visually (Mayer, 2009).

By adopting some or all of the instructional practices discussed above, the instructor is able to control the intrinsic and reduce the extraneous load sufficiently to allow for an increase in germane cognitive load, without causing cognitive overload among students. That is, the instructor has a crucial opportunity to adopt well-proven instructional techniques that facilitate schema acquisition and automation; in short, instructional designs and choices that promote effective long-term learning.

Proposition \#2: To achieve effective long-term learning, instructional practice must incorporate retrieval practice and spacing.

If intrinsic cognitive load has been managed and the extraneous load reduced, an opportunity arises to raise germane cognitive load by incorporating effective learning and teaching strategies, such as retrieval practice and spacing.

Retrieval practice are "situations in which knowledge is expressed, including situations where learners must produce the answer to a factual question, explain a concept, make an inference, apply knowledge to a new problem, and produce creative and innovative ideas" (Karpicke \& Grimalidi, 2012). In situations such as these, students must be encouraged to selfquiz, recall and draw on past experiences to address current problems. The instructor may provide immediate feedback and students may be incited to self-grade and discuss gaps in 
knowledge with their peers. The retrieval process needs to occur after a learning event (a tutorial, a lecture, etc.) took place and after a "forgetting" period of time, which could be measured in hours or days (Storm et al., 2010); that is, the student is more likely to remember, make and strengthen connections between concepts and be able to re-apply the information in a new future situation, if partial forgetting has occurred in between.

There is much evidence for the benefit of retrieval practice (Karpicke \& Roediger 2007; Lyle \& Crawford, 2011; Roediger \& Butler, 2011; Brame \& Biel, 2015). Lyle and Crawford (2011) examined for instance the effects of retrieval practice on student learning in an undergraduate statistics class. On average, students practicing retrieval performed about 8 percent higher on exams over the course of the semester than students in sections that did not use retrieval practice. In a study by Karpicke and Grimaldi, (2012), repeated retrieval during learning enhanced long-term retention. In another study, retrieval practice produced better performance and more learning than did elaborative study using concept mapping (Karpicke \& Blunt, 2011). Retrieval practice is therefore an important tool for deeper levels of learning. Effortful retrieval makes for deeper learning and greater retention (Brown et al; 2014).

\section{Table 2. Practical Suggestions for Retrieval Practice}

Retrieval practice involves asking students to recreate something learned in the past from memory.

1. Explain to students that trying to remember something makes memory more longlasting than other forms of studying.

2. Use low- or no-stakes quizzes (formative assessment) in class to achieve this. Encourage students to use self-tests.

3. Ask students to demonstrate learning by asking them to solve hands-on or authentic problems that require the use of the key underlying concepts and principles.

4. Make retrieval practice a normal part of learning, not a stressful event that determines a student's grade. Look for ways to make retrieval fun (e.g. jeopardy).

5. Use fill-in-the-blanks questions, rather than multiple choice, because fill-in questions require the students to retrieve information, rather than just recognizing the correct answer.

Spacing, or distributive practice, is the act of distributing retrieval practice over time thus encouraging students to avoid "cramming" and schedule shorter study sessions over a period of time (e.g. days 1, 3, and 7). Spacing is based on the application of the Forget to Learn Theory (Carey, 2014); that is, learning is strengthened when a student has time to partially forget the material before recalling it, to complete a tasks or answer a question. The main purpose of spacing is to disrupt memory loss in order to improve long-term retention. Spaced practice is in fact the opposite of absorbing large volumes of informational material in the shortest amounts of time possible. In short, spreading five hours of study time over a two weeks' period is more beneficial for long-term learning than cramming for five hours the night before an exam.

Table 3. Practical Suggestions for Spacing

Distributive practice, or spacing, involves spreading a fixed amount of study time over a longer period of time. 
1. Space practice over time, with content reviewed across weeks or months, to help students remember that content over the long-term.

2. Encourage students to plan their study times by creating term and weekly schedules with times set aside for studying.

3. Encourage students to review material from each class over time and continuously by spreading several "intense study sessions" across the week (and the term). It is, however, still a good idea for students to review the material the night before an exam.

4. Carefully structure courses, explicitly communicate it to students and provide a syllabus that makes this structure, and expectations, very clear and transparent (McGuire, 2015).

5. Design an assessment strategy that "spaces out" assignments at pivotal points during the term in a way that (1) stimulates students to practice their knowledge and skills over time, (2) helps diagnose and monitor achievement of learning outcomes, and (3) provides multiple opportunities to give constructive feedback to students. Storm, et al. (2010) argued that tests given immediately after exposure to content were beneficial but more effective if they were delayed.

6. Include short reviews in the beginning of each class, as a recap of previous material (Lowe, 2016), which may help students connect the dots.

In summary, combining spacing with self-testing allows students to further practice retrieval and such tests prevent any illusion of knowledge. These techniques all make learning more challenging as they compel students to "think" (retrieve knowledge); they also stimulate students to gauge their understanding and applicability of the content, which in turn promotes transfer of knowledge.

Proposition \#3: To achieve effective transferability of information, instructional practice must allow students to understand the context and the underlying principles of the material to be learned. Instructional practice should therefore use the principles of concrete examples, elaboration, and interleaving.

Making a link between often abstract concepts and pertinent examples helps students understand difficult ideas, thus making it easier to remember. These help them connect new information to existing knowledge

A very efficient strategy is to provide concrete examples that are relevant to student experiences (life, corporate) and their backgrounds. However, examples used have to be directly applicable to the concepts studied. Students should also be encouraged to create, find, reflect on, and share their own examples of abstract ideas discussed in class or online; a personal experience which may resonate with classmates' personal or professional circumstances for instance is more powerful and most helpful for learning.

\section{Table 4. Practical Suggestions for Concrete Examples}

Making a link between abstract concepts and examples helps students understand concepts by combining new concepts to existing schemas. 
1. Alternate concrete examples and abstract representations to help students recognize the underlying structure of the problems.

2. Ask students to apply their knowledge across multiple examples that vary in their level of concreteness or abstractness help students acquire a more flexible understanding of the concept.

3. Connect and integrate abstract representations of a concept with concrete representations of the same concept. Students have an easier time acquiring an initial understanding of a concept presented in a concrete form, but often are unable to transfer such knowledge to future situations. Alternatively, using abstract representations initially makes it harder for students to master the concept, but increases their ability to use that concept in different contexts. Combining the two is most helpful for learning.

4. Ask students to create their own problems, either making a concrete problem abstract, or making an abstract problem concrete.

5. Make concrete problems that fit the students' level of expertise. Combine this principle with completion problems as a scaffold to conventional problems. Use simplified real world examples, strip off layers of complexity.

Elaboration, as well as self-explanation, refers to the practice of students asking themselves why the information studied is accurate, as well as trying to explain the concept or procedure to themselves (Roediger, 2013). Students practice elaboration when they attempt to find additional layers of meaning in the material presented to them. By explaining and describing ideas with as many details as possible, as well as making connections to own experiences and previous material covered, students are able to acquire more complex schemas; i.e. learn more. Reflection is a combination of both retrieval of knowledge and elaboration of such knowledge. Reflection powerfully makes additional connections which allow students to strengthen their learning and skills.

\section{Table 5. Practical Suggestions for Elaboration}

By explaining and describing ideas with many details, as well as making connections to own experiences and previous materials, students are able to acquire more complex schemas.

1. Assign tasks that require explanation (answering questions about how or why something happened) or that require students to meaningfully organize material.

2. Ask questions that elicit explanations, such as those with the following question stems: why, what caused X, how did X occur. What if, what-if-not, how does X compare to $\mathrm{Y}$, why is $\mathrm{X}$ important? Use these types of questions especially when students struggle expressing explanations on their own.

3. After students have acquired basic knowledge and understanding of the material, instructors need to find opportunities to ask deeper questions and model answers to these questions in order for students to build a more complex understanding of a topic and to build deeper explanations of key concepts. Deep explanations mean explanations that focus on causal mechanisms, planning, well-reasoned arguments, and logic. 
4. Encourage students to write a list of important concepts and ideas followed by asking questions of how and why concepts and ideas work, as well as their interrelatedness.

5. Ask students to identify the interconnectedness between current concepts to ideas previously discussed, as well as how concepts and ideas are related to their own lives. Collins et al. (1989) indicated that students should be asked to search for meaning through inquiry and activity. When a student practices interrogative elaboration over a period of time, he/she is able to take advantage of the principles of retrieval practice and spacing. These help promote even deeper learning.

Interleaving is the practice of mixing related but distinct material during learning sessions, obliging students to discriminate between problems and selecting appropriate solution methods given the context (Brown et al., 2014). This approach also facilitates forgetting and results in spacing, which leads to greater storage and retrieval strengths (deeper learning). Learning improves if students study and switch between multiple concepts or problems during a single study session. One concept or problem should therefore not be examined for too long; variety is the key. Quality time on each concept/problem/topic should however be spent before switching. The general rule is to switch to a second concept before having fully-mastered the first concept (Lang, 2016). Students may also be encouraged to switch from individual to teamwork to work on related concepts. Interleaving principles should not be confused with multi-tasking. Interleaving also incorporates spacing and retrieval practice principles; together they promote content learning that last beyond a final exam and even the confines of your course.

Table 6. Practical Suggestions for Interleaving

Interleaving is the practice of mixing related but distinct material during learning sessions, forcing students to discriminate between problems and selecting the correct solution method given the context (Brown et al., 2014). Learning improves if students study and switch between multiple concepts or problems during a single study session and the general rule is to switch to a second concept before having mastered the first concept (Lang, 2016).

1. Ask students to compare problems with different surface structures that share the same underlying structure. By comparing problems students learn to perceive and remember the underlying structure (the context).

2. Alternate practice of different types of content. When teaching, ask students to alternate between different types of problems or ideas, rather than covering ideas sequentially.

3. When giving multi-step problems, encourage students to identify and label the substeps required for solving the problem. This practice increases students' ability to recognize the underlying structure of the problem and to apply the problem-solving steps to other problems.

4. Design assignments that provide a series of issues and alternative potential solutions, rather than worksheets covering a single type of problem.

5. Provide review questions during formative assessments. Students should also be given opportunities to make connections between the different types of topics that they study, thus promoting their ability to recognize contexts and discriminate between 
solution procedures.

6. Alternate practice of different types of content. When teaching, ask students to alternate between different types of problems or ideas, rather than covering ideas sequentially.

In summary, there are many ways instructors can encourage students to unwittingly use the many lessons about learning that cognitive psychology provides. Clearly, these learning and teaching strategies are very different from students' common approach to studying, as well as instructors' usual approach to teaching. These approaches are also more difficult and mentally challenging for students, so it may seem unrealistic to assume that every student can and will use these strategies voluntarily.

However, with purposeful and carefully considered instructional choices, the instructor can encourage students to adopt learning strategies that facilitate long-term and deep learning; i.e. facilitate schema acquisition and automation that leads to storage and transferability of information. This, ultimately, should be one of the critical goals of instructional design.

\section{Implementation of Strategies}

Implementation of the five learning strategies offered is most effective if they are purposely integrated into the design of the course. Using approaches such as backwards design (Wiggins \& McTighe, 2001) or integrated course design (Fink, 2003) the instructor can ensure that students learning outcomes (knowledge and skills) are achieved by carefully designing significant learning experiences and activities. Across the term, the instructor can promote deep and lasting learning by both choosing and sequencing material in order to control students' intrinsic cognitive load. However, careful consideration of content (facilitated face-to-face and/or online) is not enough.

Over the course of the term, student learning is enhanced if the introduction and review of course material is distributed (spaced) across the term, as well as purposefully interleaved with related concepts and ideas. In addition, helping students to make connections between the content covered and their own lives is crucial. Complementing core concepts with concrete examples and giving students multiple opportunities to elaborate and reflect on the material in class and in online activities is highly encouraged. The intended outcomes should also be constructively-aligned with assessment activities to ensure that retrieval practice and problemsolving activities are present during both formative and summative assessment activities.

However, effective student learning crucially depends on what activities the instructor selects for the student; what significant learning experiences (Fink, 2003) are students exposed to inside and outside of the classroom. As a concrete example of implementation, consider the issue of teaching the impact of pollution in an economics course. Although all students "know" about pollution, economic analysis of pollution (a negative externality) and other environmental issues requires prior knowledge and skills. Thus when designing the lesson plan, the instructor needs to reflect on students' prior knowledge, as well as their possible experiences with the topic (perhaps in the media). For this particular lesson, the learning outcomes might be for students to be able to (1) recall the demand and supply framework, (2) describe and explain the impact of pollution on producers and consumers, (3) apply the model to solve for the market outcome and then analyze 
the role of government. That is, the aim is to move students up Bloom's taxonomy of cognitive operations (Anderson, Krathwohl, \& Bloom, 2001).

The instructor may want to begin this lesson with a review of previous material, an opportunity to apply the principle of spacing to students' existing knowledge. There are many ways to facilitate such distributed practice; the instructor could give a review lecture - a reminder of material previously covered. A more effective approach would be to give a pre-quiz (online) or a reflection question such as identify one core concept, idea or theory that you think was important in Chapter $X$ that incites students to retrieve and interact with the material from memory. After the students are primed (reminded of the basic demand and supply framework), the instructor can introduce the new material.

Depending on what students have been asked to do before the class (e.g. watch a video or read a textbook section), the instructor's lecture may be more or less involved. The main goal of the lecture should be to build on students' existing knowledge as new concepts are sequentially introduced. The main objective of the lecture should be for students to acquire new material (Bligh, 2000) and concepts; an unplanned lecture is not a good vehicle to promote higher levels of thinking or problem-solving skills. Because of the lecture's limitations to deep student learning, the instructor should limit the length of the lecturing time to allow enough time for students to engage with the material (there is evidence that student attention begins to decline after 20 minutes). The introduction of new material should also aim to reduce the extraneous cognitive load as much as possible, reducing redundancies, disparate sources of information, and present content as a combination of verbal and visual material (e.g. a PowerPoint slide of a diagram combined with verbal description by the instructor). It is also a good idea to encourage students to take notes, by hand on paper or a mobile device.

Once familiar with the new material, students can be given activities that incorporate the learning strategies. A strategic sequence of activities might be as follows:

1. Give students a standard demand and supply diagram and ask them to draw in the impact of pollution (a negative externality), and then label all curves according to marginal private and social benefits/costs. This encourages students to make a connection to previous material (spacing, retrieval practice).

2. Ask students to first note the market outcome (previous learning) and then to describe and explain why this outcome is inefficient (undesirable) for society as a whole. Ask students to write down their explanation. Students both make connections and apply the material from the day's lecture.

3. Ask students to locate the socially-optimal outcome and then describe two government policies that could convince producers to produce the efficient amount. Solving the problem and analyzing the role of the government.

4. Give students several context-rich problems (realistic scenarios) and ask them to draw diagrams that describe the situation and then propose a solution to each of the scenarios. Make sure to mix scenarios that reference previous material, as well as scenarios that cover the current lesson material (interleaving). This activity serves as bridge between abstract examples and concrete examples.

5. Give students a newspaper article that discusses a recent pollution problem (concrete example) and then ask students to suggest solutions. Ask them to write up their recommendations and why (if time permits, have students take on the role of an environment activists trying to influence government policy). 
6. Before the end of the lesson, ask students to take a minute to write down three significant things they learned today and what remaining question(s) do they still have about the material (elaboration).

By the end of the class, students will not only have been introduced to new material, but careful consideration has been given to ensure that they were able to build on their existing schemas and make connections to both previous material and their own experiences. They also engaged with the material using the five learning strategies in order to promote deep and long-lasting learning.

\section{Conclusion}

The ultimate goal of instruction is to promote long-term learning among students, the tool is instructional design. Cognitive load theory argues that to achieve this goal, instructors must take into account the architecture of the learner's brain; i.e. the limited capacity of working memory in conjunction with a virtually unlimited long-term memory. According to cognitive load theory, learning is the construction and automation of schemas, and effective instructional design is the purposeful choice of activities that facilitate such learning.

The main objective of this study is to explore the theoretical foundations that should guide the choice of such activities. The overarching conclusion is that instructors must guard against cognitive overload, while implementing evidence-based learning strategies (spacing, retrieval practice, elaboration, interleaving, and concrete examples) that help students build schemas. The suggestions are to control the intrinsic cognitive load of the material presented by, among other things, matching the complexity of material to student expertise, and to reduce extraneous cognitive load by managing split-attention effects, lack of schema-based knowledge, redundancy, and single modality presentation.

Having controlled intrinsic load and reduced extraneous load, the instructional designer is in a position to introduce five proven learning strategies that can effectively help students successfully optimize long-lasting learning and achievement of learning outcomes.

The main contribution of this article is to propose practical, easy-to-implement but impactful suggestions to academic staff. A large body of evidence indicates that instructional material, interventions and facilitation (face-to-face and online) that take cognitive load theory into consideration have a more powerful effect on student learning. Having questioned, applied and reflected on each of these strategies in various learning environments, the study generates a set of propositions which are useful in targeting precisely those aspects of instruction that promote long-term learning. Suggestions for further research in the context of this article would include more empirical research in order to strengthen the link between cognitive load theory and instructional practice in general, and the need for a comprehensive methodology that would help measure cognitive load on all stages of instruction.

In conclusion, instructors must make well-informed decisions about what material to select and how to present it to their students. Applying cognitive load research while making these decisions encourages instructors to design and adopt material according to its cognitive impact.

This study therefore advocates purposeful planning and strategic design of instructional material that foster and expand students' germane load, in order to promote deeper and longlasting learning. 


\section{References}

Anderson, L. W., Krathwohl, D. R. and Bloom, B. S. (2001). A taxonomy for learning, teaching, and assessing: A revision of Bloom's taxonomy of educational objectives. Boston, MA: Allyn \& Bacon

Baddeley, A. (2010). Working memory. Current Biology, 20(4), R136-R140.

Bligh, A. B. (2000). What's the use of lectures? San Francisco, CA: Jossey-Bass

Brame, C. J. and Biel, R. (2015). Test-enhanced learning: The potential for testing to promote greater learning in undergraduate science courses. CBE-Life Sciences Education, 14, 1-12.

Brown, P. C., Roediger, H. L. and McDaniel, M.A. (2014). Make it stick. Harvard University Press.

Carey, B. (2014). How We Learn: The Surprising Truth about When, where and why it Happens. Pan Macmillan.

Chandler, N. J. and Sweller, J. (1992). The Split-Attention Effect as a Factor in the Design of Instruction: A Review and Qualitative Synthesis. British Journal of Educational Psychology, 62(2): 233-246.

Cowan, N. (2001). The magical number 4 in short-term memory: A reconsideration of mental storage capacity. Behavioral and Brain Sciences. 24, 87-114.

Deans for Impact. (2015). The Science of Learning. Austin, TX: Deans for Impact.

Debue, N. and van de Leemput, C. (2014). What does germane load mean? An empirical contribution to the cognitive load theory. Frontiers in Psychology, 5, 1099.

http://doi.org/10.3389/fpsyg.2014.01099

DeWinstanley, P. A. and Bjork, R.A. (2002). Successful lecturing: Presenting information in ways that engage effective processing. New Directions for Teaching and Learning, 2002(89), 1931.

De Jong, T. (2010). Cognitive load theory, educational research, and instructional design: Some food for thought. Instructional Science, 38: 105-134.

Fink, L. D. (2003). Creating significant learning experiences: An integrated approach to designing college courses. San Francisco, CA: Jossey-Bass

Karpicke, J. D. and Grimaldi, P.J. (2012). Retrieval-based learning: A perspective for enhancing meaningful learning. Educational Psychology Review, 24(3), 401-418. 
Karpicke, J. D. and Roediger, H.L. (2008). The critical importance of retrieval for learning. Science, 319(5865), 966-968.

Karpicke, J. D. and Roediger, H.L. (2007). Expanding retrieval practice promotes short-term retention, but equally spaced retrieval enhances long-term retention. Journal of Experimental Psychology: Learning, Memory, and Cognition, 33(4), 704.

Kirschner, P.A., Sweller, J. and Clark, R.E. (2006). Why Minimal Guidance During Instruction Does Not Work: An Analysis of the Failure of Constructivist, Discovery, Problem-Based, Experiential, and Inquiry-Based Teaching. Educational Psychologist, 41(2), 75-86.

Lang, J. M. (2016). Small Teaching. San Francisco, CA: Jossey-Bass.

Lowe, D. (2016). Remembrance of Philosophy Classes Past: Why Cognitive Science Suggests that a Brief Recap Is the Best Way to Start Each Class Day. Teaching Philosophy, 39(3), 279289.

Lyle, K. B. and Crawford, N.A. (2011). Retrieving essential material at the end of lectures improves performance on statistics exams. Teaching of Psychology, 38(2), 94-97.

Mayer, R.E. (2004). Should there be a three-strike rule against pure discovery learning? American psychologist, 59(1), 14.

McGuire, S. Y. (2015). Teach Students how to Learn: Strategies You Can Incorporate Into Any Course to Improve Student Metacognition, Study Skills, and Motivation. Stylus Publishing, LLC.

Miller, G. A. (1956). The magical number seven, plus or minus two: Some limits on our capacity for processing information. Psychological Review, 63: 81-97.

Moreno, R. (2006) Learning in High-Tech and Multimedia Environments. Current Directions in Psychological Science. 15(2): 63-67.

Pashler, H., Bain, P. M., Bottge, B. A., Graesser, A., Koedinger, K., McDaniel, M. and Metcalfe, J. (2007). Organizing Instruction and Study to Improve Student Learning. IES Practice Guide. NCER 2007-2004. National Center for Education Research.

Pashler, H., Rohrer, D., Cepeda, N. J. and Carpenter, S.K. (2007). Enhancing learning and retarding forgetting: Choices and consequences. Psychonomic bulletin \& review, 14(2), 187-193.

Peterson, L. and Peterson, M. (1959). Short-term Retention of Individual Verbal Items. Journal of Experimental Psychology. 58, 193-198.

Roediger, H. L. and Butler, A.C. (2011). The critical role of retrieval practice in long-term retention. Trends in cognitive sciences, 15(1), 20-27.

Roediger, H. L. and Karpicke, J.D. (2006). Test-enhanced learning taking memory tests improves long-term retention. Psychological science, 17(3), 249-255. 
Hultberg, Santandreu Calonge and Lee

Storm, B. C., Bjork, R. A. and Storm, J.C. (2010). Optimizing retrieval as a learning event: When and why expanding retrieval practice enhances long-term retention. Memory \& Cognition, 38(2), 244-253.

Sweller, J. (1988). Cognitive Load During Problem Solving: Effects on Learning. Cognitive Science, 12, 257-285.

Sweller, J. (1994). Cognitive Load Theory, Learning Difficulty, and Instructional Design. Learning and Instruction, 4: 295-312.

Wiggins, G. and McTighe, J. (2001). What is Backward Design? In G. Wiggins \& J. McTighe’s Understanding by Design (p. 7 - 19). Upper Saddle River, NJ: Prentice Hall.

Zull, J.E. (2002). The Art of Changing the Brain: Enriching Teaching by Exploring the Biology of Learning, Virginia: Stylus Publishing. 